\title{
Hair cortisol-a method to detect chronic cortisol levels in patients with Prader-Willi syndrome
}

Hasanain Hamid Shukur ${ }^{1 *}$ (D), Yolanda B. de Rijke $e^{2,4}$, Elisabeth F. C. van Rossum ${ }^{3,4}$, Laith Hussain-Alkhateeb ${ }^{5}$ and Charlotte Höybye 1,6 $^{1,6}$

\begin{abstract}
Background: Prader-Willi syndrome (PWS) is a multisymptomatic, rare, genetic, neurodevelopmental disorder in adults mainly characterized by hyperphagia, cognitive dysfunction, behavioral problems and risk of morbid obesity. Although endocrine insufficiencies are common, hypocortisolism is rare and knowledge on long-term cortisol concentrations is lacking. The aim of this study was to evaluate long-term cortisol levels in PWS by measurements of hair cortisol.

Methods: Twenty-nine adults with PWS, 15 men and 14 women, median age 29 years, median BMI $27 \mathrm{~kg} / \mathrm{m}^{2}$, were included. Scalp hair samples were analyzed for cortisol content using liquid-chromatography tandem-mass spectrometry. In addition, a questionnaire on auxology, medication and stress were included. For comparison, 105 age- and sex-matched participants from the population-based Lifelines Cohort study were included as controls. The mean hair cortisol between the groups were compared and associations between BMI and stress were assessed by a generalized linear regression model.

Results: In the PWS group large variations in hair cortisol was seen. Mean hair cortisol was $12.8 \pm 25.4 \mathrm{pg} / \mathrm{mg}$ compared to $3.8 \pm 7.3 \mathrm{pg} / \mathrm{mg}$ in controls $(p=0.001)$. The linear regression model similarly showed higher cortisol levels in patients with PWS, which remained consistent after adjusting for BMI and stress $(p=0.023)$. Furthermore, hair cortisol increased with BMI $(p=0.012)$ and reported stress $(p=0.014)$.

Conclusion: Long-term cortisol concentrations were higher in patients with PWS compared to controls and increased with BMI and stress, suggesting an adequate cortisol response to chronic stress. Hair cortisol demonstrate promising applications in the context of PWS treatment and disease management.
\end{abstract}

Keywords: Prader-Willi syndrome, Hair cortisol, Chronic stress, Obesity

\footnotetext{
* Correspondence: hasanain.shukur@ki.se

'Department of Molecular Medicine and Surgery, Karolinska Institute, Stockholm, Sweden

Full list of author information is available at the end of the article
}

C C The Author(s). 2020 Open Access This article is licensed under a Creative Commons Attribution 4.0 International License, which permits use, sharing, adaptation, distribution and reproduction in any medium or format, as long as you give appropriate credit to the original author(s) and the source, provide a link to the Creative Commons licence, and indicate if changes were made. The images or other third party material in this article are included in the article's Creative Commons licence, unless indicated otherwise in a credit line to the material. If material is not included in the article's Creative Commons licence and your intended use is not permitted by statutory regulation or exceeds the permitted use, you will need to obtain permission directly from the copyright holder. To view a copy of this licence, visit http://creativecommons.org/licenses/by/4.0/ The Creative Commons Public Domain Dedication waiver (http://creativecommons.org/publicdomain/zero/1.0/) applies to the data made available in this article, unless otherwise stated in a credit line to the data. 


\section{Background}

Prader-Willi syndrome (PWS, OMIM 176270) is a rare, complex neurodevelopmental disorder with a reported incidence of approximately 1 in 15,000-30,000 newborns [1]. PWS is caused by a lack of expression of paternally inherited genes in the q11-q13 region of chromosome 15, most commonly caused by a paternal deletion or a maternal disomy $[1,2]$. PWS in adults is characterized by muscular hypotonia, hyperphagia requiring restricted diet and regular physical activity to prevent the development of severe obesity [3]. Other features include a mild to moderate intellectual disability, a distinct behavioral phenotype with stubbornness, temper tantrums, obsessive and compulsive behaviors and mood instability $[4,5]$.

Many of the symptoms in PWS are believed to be caused by a dysfunction of the hypothalamus. Endocrine abnormalities are common including deficiencies in growth hormone, sex hormones and thyroid hormones. Concerning, the function of the hypothalamus-pituitary-adrenal (HPA) axis both normal function and partial central adrenal insufficiency have been reported [6-11].

In previous studies, different tests were used to evaluate the function of the HPA-axis. They were all based on acute variations in adrenocorticotropic hormone (ACTH) and/or cortisol, whereas information about cortisol concentrations over a longer period is lacking. Due to the intellectual disability and behavior problems in PWS it is also of great value to find other approaches for evaluating the HPA axis in PWS than the conventional tests. By measuring cortisol in hair, the average cortisol concentrations over longer periods can be assessable using an easy, non-invasive and convenient procedure [12].

The aim of this study was to examine hair cortisol in a group of adults with PWS in comparison to populationbased controls. Self-reported clinical parameters from a semi-structured questionnaire were included for further evaluation.

\section{Methods}

\section{Participants and procedures}

Twenty-nine adults (older than 18 years of age) with PWS were enrolled in 2015 and 2016 either during routine visits to the Department of Endocrinology, Karolinska University Hospital, Stockholm, or after responding to advertisements in the journal of the Swedish PWS Association.

Data for controls were retrieved from the Lifelines Cohort Study. Lifelines is a multi-disciplinary prospective population-based cohort study examining the health and health-related behaviors of 167,729 persons living in the North of The Netherlands [13-15]. Lifelines comprises a broad range of data, including hair cortisol which was available for 266 individuals, who were used as controls in the present study [15].

\section{Hair processing and analysis}

In summary, a hair sample (100-150 hairs) was cut from the posterior vertex of the scalp, as close to the scalp as possible. The hair sample was stored on a paper in an envelope until analysis [13]. For the analysis of hair cortisol, the proximal $3 \mathrm{~cm}$ of the hair $(10 \mathrm{mg})$ was cut into $1 \mathrm{~cm}$ segments, which were washed in isopropanol, and then left to dry [13]. Methanol was used to extract cortisol and after purification, cortisol was quantified by liquid chromatography - tandem mass spectrometry (LC-MS/MS) (Waters, Milford, MA) [16]. Two standard curves were identified from ten calibration standards on each day of analysis and the functional sensitivity (lower limit of quantification, LLoQ (pg/mg)) was calculated by serial dilution from $40 \mathrm{mg} / \mathrm{ml}$ to $0.3125 \mathrm{mg} / \mathrm{ml}$ [16]. The geometric mean of hair cortisol analyses in The Lifelines Cohort study $(N=266)$ was $2.7 \mathrm{pg} / \mathrm{mg}$ [13].

\section{Questionnaire}

The participants with PWS and/or their caretakers, filled out a questionnaire about their age, sex and anthropometric measurements. This questionnaire was not developed for this study, but has been used for multiple studies in the past.

[15]. The stress was assessed by the question: did any stressful events occur during the last 3 months? In case there did, what happened?

In addition, the participants were asked in a standardized manner whether they used any product containing corticosteroids in the past 3 months and the route of administration (i.e., oral, intravenous, nasal, topical, inhaled, joint injections or others).

Data retrieved from the Lifelines Study for the controls included information on the subjects' age, sex, anthropometric and stressful life events. Life events were evaluated using the Dutch version of the List of Threatening Experiences (LTE), including occurrence of twelve major life events in the past 12 months [13].

\section{Matching process and statistical analysis}

The PWS patients were categorized into four age-groups [(18-25 years), (26-35 years), (36-45 years) and (46-60 years)], resulting in a fairly balanced age-sex groups for each of the approximately 10 years intervals. Subjects from each group of PWS patients were matched for age and sex to a total of 105 subjects from the corresponding control groups, in a 1:5 ratio. However, due to low number of controls for males in the 18-25 age-group (9 adults with PWS, 23 matched-controls) matching was made in a ratio of 1:2.5 for this particular sex-age group. The matching was programmed using the "seed" command in STATA 15.0 to ensure a random selection of subjects. 
Results are presented as mean \pm SD. For comparison between the groups, Student's t-test was used. Mean hair cortisol was considered to best capture the clinical reality with large variations in hair cortisol and a generalized linear regression model was used to examine the association of crude levels and levels adjusted for BMI and stress as potential confounders. The Akaike Information Criteria (AIC) test was used to confirm best fit model where by both BMI and reported stress were retained in the model, as they predicted the model well. Statistical significance was set at $p<0.05$.

\section{Results}

Twenty-nine adults (15 men and 14 women) with confirmed PWS participated. Mean (SD) for age was 33.4 years (12.7) in the patients with PWS and 42.1 (11.6) years in the controls. By virtue of the matching process based on the sex-age groups, there were no significant differences between the patients with PWS and controls with respect to age and sex.

In the lifelines Cohort Study median BMI was $26 \mathrm{~kg} /$ $\mathrm{m} 2,42 \%$ were overweight and 19\% obese [15]. Twelve percent reported use of steroids the past 3 months and $58 \%$ reported at least one life event during the past 12 months [15].

Individual hair cortisol levels in patients with PWS are displayed in Table 1. Six patients with PWS had hair cortisol levels $>10 \mathrm{pg} / \mathrm{mg}$ and all but two of them reported occurrence of stressful situations. Seven reported use of steroids without hair cortisol being suppressed (hair cortisol 2.0 to $39.1 \mathrm{pg} / \mathrm{mg}$ ) and all but one reported stress.

Table 1 Characterization of 29 patients with Prader-Willi syndrome, as a heat map table, sorted according to the levels of hair

\begin{tabular}{|c|c|c|c|c|}
\hline Patient code & Hair cortisol pg/mg & BMI & Stress & Corticosteroids \\
\hline 26 & 105,6 & 40,0 & yes & 0 \\
\hline 12 & 90 & 26,0 & yes & 0 \\
\hline 18 & 39,4 & 28,0 & yes & Inhalation \\
\hline 1 & 36,1 & 32,0 & no & Cream ointment for eczema \\
\hline 7 & 12,5 & 26,0 & yes & 0 \\
\hline 14 & 11,4 & 22,0 & no & 0 \\
\hline 10 & 10 & 35,0 & no & 0 \\
\hline 6 & 8,5 & 20,0 & yes & Ointment \\
\hline 5 & 7,7 & 20,0 & yes & Ointment \\
\hline 28 & 7,6 & 45,0 & no & 0 \\
\hline 21 & 5,6 & 27,0 & no & 0 \\
\hline 20 & 3,3 & 27,0 & no & 0 \\
\hline 13 & 3,2 & 28,0 & yes & Very few ointment cream \\
\hline 27 & 3 & 39,0 & Yes & Nasal spray \\
\hline 8 & 2,7 & 23,0 & no & Very few ointment cream \\
\hline 11 & 2,1 & 24,0 & no & 0 \\
\hline 19 & 2,1 & 23,0 & yes & 0 \\
\hline 3 & 2 & 48,0 & no & 0 \\
\hline 4 & 1,9 & 32,0 & yes & 0 \\
\hline 25 & 1,9 & 32,0 & yes & 0 \\
\hline 23 & 1,8 & 23,0 & yes & 0 \\
\hline 29 & 1,5 & 24,0 & yes & 0 \\
\hline 9 & 1,4 & 24,0 & yes & 0 \\
\hline 24 & 1,3 & 31,0 & no & 0 \\
\hline 22 & 1,3 & 39,0 & no & 0 \\
\hline 2 & 1,3 & 33,0 & no & 0 \\
\hline 15 & 1,3 & 37,0 & no & 0 \\
\hline 16 & 1,3 & 25,0 & no & 0 \\
\hline 17 & 1,3 & 18,0 & no & 0 \\
\hline
\end{tabular}


Thirteen other adults with hair cortisol of $10 \mathrm{pg} / \mathrm{mg}$ and below had not experienced any stress, and the remaining ten adults reported different kinds of stress that did not result in high levels of hair cortisol. Six patients with hair cortisol $<1.3 \mathrm{pg} / \mathrm{mg}$ did not report any stress or use of glucocorticoids. Figure 1 shows the hair cortisol in patients with PWS with and without reported stress.

There was a large variation in hair cortisol levels in the patients with PWS. Mean hair cortisol in all patients with PWS was $12.8 \pm 25.4 \mathrm{pg} / \mathrm{mg}$ compared to $3.8 \pm 7.3$ $\mathrm{pg} / \mathrm{mg}$ in the controls $(p=0.001)$. When the two high readings were excluded mean hair cortisol in the PWS group was $6.43 \pm 9.66 \mathrm{pg} / \mathrm{mg}$. In the crude regression model, hair cortisol in patients with PWS was significantly higher compared to the controls $(\beta=1.21 ; 95 \% \mathrm{CI}$ [0.44-1.98] $)(p=0.002)$ and remained higher after adjusting for BMI and reported stress $(\beta=0.84 ; 95 \% \mathrm{CI}$ [0.11-1.56], $p=0.023$ ) (Table 2).

Using the same linear regression model in patients with PWS, hair cortisol increased with BMI $(\beta=0.05$; 95\% CI [0.02-0.09], $p=0.002$, which remained after adjustment for stress ( $\beta=0.04 ; 95 \%$ CI $[0.01-0.08], p=$ 0.012) (Table 2). Likewise, hair cortisol increased with stress $(\beta=1.16 ; 95 \%$ CI $[0.41-1.91], \mathrm{p}=0.002)$, which remained after adjustment for BMI $(\beta=0.90(95 \% \mathrm{CI}$ [0.19-1.60], $p=0.014$ ) (Table 2).

\section{Discussion}

In this study of 29 adults with PWS, mean hair cortisol levels were significantly higher than hair cortisol in 105

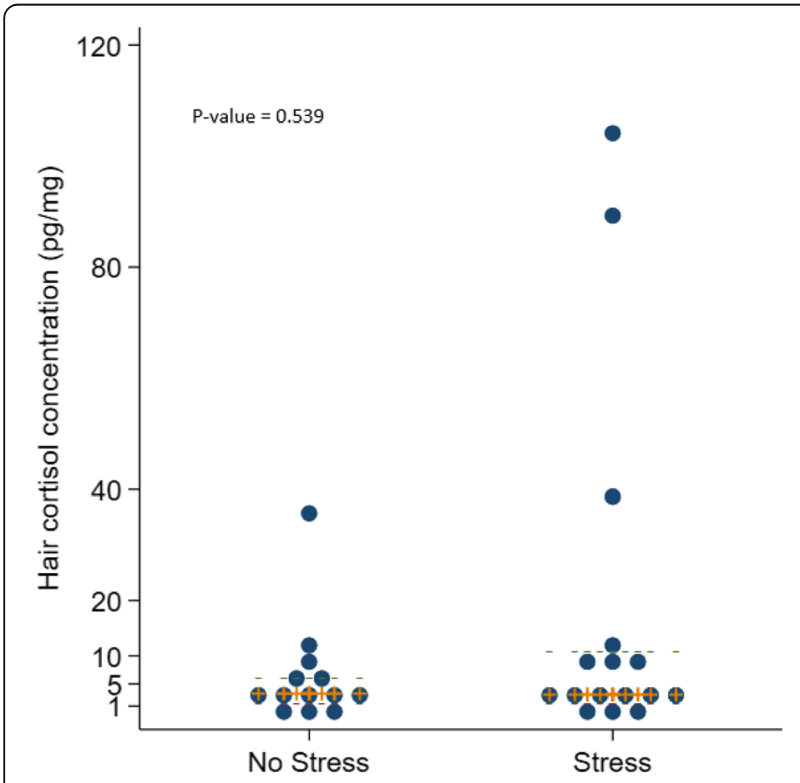

Fig. 1 Swarm plot of hair cortisol in 29 patients with Prader-Willi syndrome with or without stress, displaying the median (IQR) and included a $p$-value sex and age matched population-based controls. Hair cortisol increased with BMI and reported stress in patients with PWS.

The stress hormone cortisol, produced in the adrenals, is important in maintaining body homeostasis by modulating neuroendocrine functions, the sympathetic nervous system and the immune function. Cortisol levels are regulated by activity in the hypothalamus and pituitary and secreted in a pulsatile circadian rhythm with increased secretion in response to stress. Cortisol is commonly measured in blood, and saliva, but these methods only reflect the time point at which the sampling is done or when measured in urine the past $24 \mathrm{~h}$ ' cortisol production. Multiple samplings are often needed. However, during the past decade, the measurement of hair cortisol has emerged as a non-invasive method to estimate the cortisol concentrations over months $[6,14,17]$. Hair grows at a relatively stable rate of approximately $1 \mathrm{~cm} / \mathrm{month}$, and cortisol accumulates in hair. Thus, cortisol in hair retrospectively represents the average cortisol level over the corresponding period. There is no discomfort associated with collection of the hair sample and no special storage precautions are required for the samples. This is an attractive procedure, especially in a population such as PWS where the psychological and behavioral features might complicate advanced sampling procedures. We found that collection of the hair samples worked out well in our PWS cohort, although some men could not participate because of too short hair for sufficient analyses. In addition, four patients declined participation because they felt that even the small hairless spot on the scalp after cutting the hair would stigmatize them further, although the sampling spot at the back of the scalp is usually too small to be visible afterwards. In our cohort of patients with PWS, hair cortisol levels were clearly increased in patients who had reported significant stressful events. This is in accordance with several studies showing that the content of cortisol in hair is higher in individuals exposed to stress and stress-related disorders [12, 17-24]. Some of the patients in the present study with normal to low normal hair cortisol reported nonspecific stressful situations, but the analysis of hair cortisol was probably not sensitive enough to detect minor or short-lived alterations of the HPA-axis [25].

Cortisol levels have been found to correlate positively with waist to hip ratio, waist circumference and BMI [19, 26-30] and to be higher in obese individuals compared to normal-weight people [28, 29]. To retain all patients with PWS in the statistical analyses, matching for BMI between patients with PWS and controls was not done since some severely obese patients with PWS could not be matched with controls. However, similar to previous studies, we found an increase in hair cortisol with BMI in the patients with PWS [30]. 
Table 2 Crude and adjusted regression Coefficients and 95\% Confidence intervals (Cl) using a linear regression model for hair cortisol (pg/mg), in 29 patients with Prader-Willi syndrome (PWS) and 105 age- and sex-matched controls

\begin{tabular}{|c|c|c|c|c|}
\hline & \multicolumn{2}{|l|}{ Crude } & \multicolumn{2}{|l|}{ Adjusted $^{b}$} \\
\hline & Regression Coefficients $\beta$ (95\% Cl) & $P$-value & $\begin{array}{l}\text { Regression Coefficients } \\
\text { B }(95 \% \mathrm{Cl})\end{array}$ & $P$-value \\
\hline $\begin{array}{l}\text { Controls } \\
\text { PWS }\end{array}$ & $\begin{array}{l}\text { Reference } \\
1.21(0.44-1.98)\end{array}$ & 0.002 & $\begin{array}{l}\text { Reference } \\
0.84(0.11-1.56)\end{array}$ & 0.023 \\
\hline $\begin{array}{l}\text { PWS } \\
\text { BMI } \mathrm{kg} / \mathrm{m}^{2} \text { a }\end{array}$ & $0.05(0.02-0.09)$ & 0.002 & $0.04(0.01-0.08)$ & 0.012 \\
\hline $\begin{array}{l}\text { PWS } \\
\text { Stress } \\
\text { Yes }\end{array}$ & $1.16(0.41-1.91)$ & 0.002 & $0.90(0.19-1.60)$ & 0.014 \\
\hline
\end{tabular}

aMl (Body Mass Index)

badjusted for BMI and stress

It is well known that some patients with PWS suffer from diseases secondarily to obesity, such as diabetes, cardiovascular diseases, respiratory diseases and arthrosis [31], and PWS is associated with a decreased life expectancy, with an annual death rate reported to be as high as $3 \%[32,33]$. Nevertheless, a number of reported deaths were unexpected and unexplained, and it has been speculated if central adrenal insufficiency might have been the cause of some of the deaths [6]. While the ACTH stimulation test provides information about the maximum response of the adrenal gland under stress hair cortisol concentrations provide information about average cortisol concentrations over a longer period. Our results warrant for larger and potentially randomized studies, but measurement of hair cortisol in PWS is attractive due to its non-invasive and simple performance. It is also an advantage that hair cortisol gives information on long-term cortisol exposure and might in the future be a baseline test for evaluation of the adrenal function and consideration for further evaluation.

\section{Limitations}

PWS is a rare disease, and the number of participants in the present study was too small for more complex analyses and comparisons with the control group. Furthermore, detailed information on use of steroids was not realistic to obtain and for robust information a prospective study would be necessary. Hair cortisone was not analyzed, but as hair cortisol and hair cortisone strongly correlate [30], the added value of measuring cortisone for the purpose of the present study would probably be limited.

Another limitation in our study is the assessment of stress, which in both groups was interpreted from reported stress during different duration of time and different questionnaires, which potentially might have affected the results. Moreover, in the PWS group most of the questionnaires were answered by the patients' caretakers and not directly by themselves. The questions on stress were not validated in patients with PWS but they were adapted to the capacity of this group of patients and therefore very simple to answer and the answers were confirmed by the caregivers. However, this is a pilot study and for the purpose of our study we were interested in whether stressful situations at all would elicit an increase in cortisol. Finally, patients with PWS who were able and willing to participate, might represent a selected group of quite healthy and well-functioning adults with PWS.

\section{Conclusion}

In conclusion, in our adult patients with PWS the variation in hair cortisol was large. The mean cortisol level was higher than in the age and sex matched populationbased controls. Increased BMI and reported stress were both associated with increased hair cortisol levels. The function of the HPA axis in PWS is an ongoing issue and there is a need for further investigations. Among these to study the long-term cortisol exposure and the effect of stress. The present study is the first to analyze hair cortisol in PWS, and our results suggest an adequate long-term cortisol level and cortisol response to chronic stress in PWS. Hair cortisol might become a useful tool to guide the monitoring and management efforts for adults with PWS, including follow-up of comorbidities.

\section{Abbreviations}

PWS: Prader-Willi syndrome; HPA axis: Hypothalamus pituitary adrenal axis; BMI: Body mass index; ACTH: Adrenocorticotropic hormone

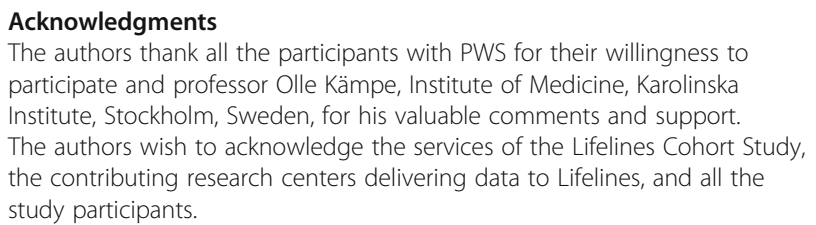

Authors' contributions

"HHS" and " $\mathrm{CH}$ " enrolled the patients with PWS. All authors ("HHS", "CH",

"YBDR", "EFCVR","LHA") were involved in stu1dy design, statistical analysis, 
interpreting data and manuscript drafting and read and approved the final manuscript.

\section{Funding}

EFCVR is funded by a Vidi grant from the Netherlands Organization of Scientific Research NWO (grant number: 91716453). Open Access funding provided by Karolinska Institute.

\section{Availability of data and materials}

The data that support the findings of this study are available on request from the corresponding author. The data are not publicly available due to privacy or ethical restrictions. Data from controls are kept by the Lifelines Cohort study, the Netherlands. The permission for access to the raw data from the Lifelines cohort study was granted by the Lifelines' research office.

\section{Ethics approval and consent to participate}

The present study was approved by the Ethical Committee in Stockholm, Karolinska Institutet, 2014/1995-31/4. All participants and guardians provided their written informed consent before any study procedures were performed.

All the patients and their guardians signed an informed consent that their personal information would be coded, and that the study results could be published using this code.

\section{Consent for publication}

Not applicable.

\section{Competing interests}

The authors declare that there is no conflict of interest.

\section{Author details}

'Department of Molecular Medicine and Surgery, Karolinska Institute, Stockholm, Sweden. 'Department of Clinical Chemistry, Erasmus MC, University Medical Center Rotterdam, Rotterdam, The Netherlands. ${ }^{3}$ Department of Medicine, Division of Endocrinology, Erasmus MC, University medical Center Rotterdam, Rotterdam, The Netherlands. ${ }^{4}$ Obesity Center CGG, Erasmus MC, University Medical Center Rotterdam, Rotterdam, The Netherlands. ${ }^{5}$ School of Public Health and Community Medicine, Institute of Medicine, Sahlgrenska Academy, University of Gothenburg, Gothenburg, Sweden. ${ }^{6}$ Patient Area Endocrinology and Nephrology, Inflammation and Infection Theme, Karolinska University Hospital, Stockholm, Sweden.

Received: 28 May 2020 Accepted: 26 October 2020

\section{Published online: 10 November 2020}

\section{References}

1. Deal C, Tony M, Höybye C, Allen DB, Tauber M, Christiansen JS. Growth hormone research society workshop summary: consensus guidelines for recombinant human growth hormone therapy in Prader-Willi syndrome. J Clin Endocrinol Metab. 2013;98(6):E1072-87.

2. Cassidy SB, Schwartz S. Prader-Willi and Angelman syndromes. Disorders of genomic imprinting. Medicine (Baltimore). 1998;77:140-51.

3. Goldstone AP, Holland AJ, Hauffa BP, Hokken-Koelega AC, Tauber M. Recommendations for the diagnosis and management of Prader-Willi syndrome. J Clin Endocrinol Metab. 2008;93(11):4183-97.

4. Ho AY, Dimitropoulos A. Clinical management of behavioral characteristics of Prader-Willi syndrome. Neuropsychiatr Dis Treat. 2010;6:107-18.

5. Burman P, Ritzen EM, Lindgren AC. Endocrine dysfunction in Prader-Willi syndrome: a review with special reference to GH. Endocr Rev. 2001;22:787-99.

6. De Lind van Wijngaarden RF, Otten BJ, Festen DA, Joosten KF, de Jong FH, Sweep FC, Hokken-Koelega AC. High prevalence of central adrenal insufficiency in patients with Prader-Willi syndrome. J Clin Endocrinol Metab. 2008:93:1649-54.

7. Rosenberg AGW, Pellikaan K, Poitou C, Goldstone AP, Høybye C, Markovic T. et al. Central adrenal insufficiency is rare in Prader-Willi syndrome. J Clin Endocrinol Metab. 2020 Mar 31. pii: dgaa168. doi: https://doi.org/10.1210/ clinem/dgaa168.

8. Grugni G, Beccaria L, Crino A, Crino A, Cappa M, De Medici C, et al. Central adrenal insufficiency in young adults with Prader-Willi syndrome. Clin Endocrinol. 2013. https://doi.org/10.1111/cen.12150.
9. Nyunt O, Cotterill AM, Archbold SMWJY, Leong GM, Verge CF, et al. Normal cortisol response of low-dose synacthen $(1 \mathrm{microg})$ test in children with Prader-Willi syndrome. J Clin Endocrinol Metab. 2008;95:E464-7.

10. Farholt S, Sode-Carlsen R, Christiansen JS, Östergaard JR, Höybye C. Normal cortisol response to high-dose synacthen and insulin tolerance test in children and adults with Prader-Willi syndrome. J Clin Endocrinol Metab. 2011;96:E173-80.

11. Obrynba KS, Hoffman RP, Repaske DR, Anglin K, Kamboj MK. No central adrenal insufficiency found in patients with Prader-Willi syndrome with an overnight metyrapone test. J Pediatr Endocrinol Metab. 2018;31(7):809-14.

12. Manenschijn L, Koper JW, Lamberts SW, van Rossum EF. Evaluation of a method to measure long term cortisol levels. Steroids. 2011;76:1032-6.

13. Stolk RP, Rosmalen JG, Postma DS, de Boer RA, Navis G, Slaets JP, et al. Universal risk factors for multifactorial diseases: lifelines: a three-generation population-based study. Eur J Epidemiol. 2008;23:67-74.

14. Scholtens S, Smidt N, Swertz MA, Bakker SJ, Dotinga A, et al. Cohort profile: a lifelines, a three-generation cohort study and biobank. Int J Epidemiol. 2015. https://doi.org/10.1093/ije/dyu229.

15. Wester VL, Noppe G, Savas M, van den Akker ELT, de Rijke YB, van Rossum EFC, et al. Hair analysis reveals subtle HPA axis suppression associated with use of local corticosteroids: the lifelines cohort study. J Psyconeuroendocrinology. 2017;80:1-6.

16. Noppe G, de Rijke YB, Dorst K, Van den Akker EL, Rossum EF. LC-MS/MSbased method for long-term steroid profiling in human scalp hair. Clin Endocrinol. 2015;83:162-6.

17. Kalra S, Einarson A, Karaskov T, Van Uum S, Koren G. The relationship between stress and hair cortisol in healthy pregnant women. Clin Invest Med. 2007;30:E103-7.

18. Yamada J, Stevens B, de Silva N. Hair cortisol as a potential biologic marker of chronic stress in hospitalized neonates. Neonatology. 2007;92:42-9.

19. Noppe G, van den Akker EL, de Rijke YB, Koper JW, Jaddoe WW, van Rossum $E F$, et al. Long-term glucocorticoid concentrations as a risk factor for childhood obesity and adverse body-fat distribution. Int J Obes. 2016. https://doi.org/10.1038/ijo.2016.113.

20. Van Uum SH, Sauvé B, Fraser LA, Morley-Forster P, Paul TL, Koren G. Elevated content of cortisol in hair of patients with severe chronic pain: a novel biomarker for stress. Stress. 2008;11:483-8.

21. Dettenborn L, Tietze A, Bruckner F, Kirschbaum C. Higher cortisol content in hair among long-term unemployed individuals compared to controls. Psychoneuroendocrinology. 2010;35:1404-9.

22. Manenschijn L, van Kruysbergen RG, de Jong FH, Koper JW, van Rossum EF. Shift work at young age is associated with elevated long-term cortisol levels and body mass index. J Clin Endocrinol Metab. 2011:96:E1862-5.

23. Manenschijn L, Schaap L, van Schoor NM, van der Pas S, Peeters GM, Lips P, et al. High long-term cortisol levels, measured in scalp hair, are associated with a history of cardiovascular disease. J Clin Endocrinol Metab. 2013;98:2078-83.

24. Staider T, Steudtle Schmiedgen S, Alexander N, Alexander N, Klucken T, Vater $A$, et al. Stress-related and basic determinants of hair cortisol in humans: a meta-analysis. Psychoneuroendocrinology. 2017. https://doi.org/ 10.1016/j.psyneuen.2016.12.017

25. Russell E, Koren G, Rieder M, Van Uum S. Hair cortisol as a biological marker of chronic stress: current status, future directions and unanswered questions. Psychoneuroendocrinology. 2012;37(5):589-601.

26. Veldhorst MA, Noppe G, Jongejan MH, Jongejan MH, Kok CB, Mekic S, Koper JW, et al. Increased scalp hair cortisol concentrations in obese children. J Clin Endocrinol Metab. 2014 Jan;99(1):285-90.

27. Feller S, Vigl M, Bergmann MM, Boeing H, Kirschbaum C, Stadler T, et al. Predictors of hair cortisol concentrations in older adults. Psychoneuroendocrinology. 2014 Jan; 39:132-40. https://doi.org/10.1016/j.psyneuen.2013.10.007.

28. Wester VL, Staufenbiel SM, Veldhorst MAB, Visser JA, Manenschijn L, Koper $J W$, et al. Long-term cortisol levels measured in scalp hair of obese patients. Obesity. 2014. https://doi.org/10.1002/oby.20795.

29. Stalder T, Steudte S, Alexander N, Miller R, Gao W, Dettenborn L, Kirschbaum C. Cortisol in hair, body mass index and stress-related measures. Biol Psychol. 2012 Jul; $90(3): 218-23$.

30. Staufenbiel SM, Penninx BW, de Rijke YB, van den Akker EL, van Rossum EF. Determinants of hair cortisol and hair cortisone concentrations in adults. Psychoneuroendocrinology. 2015;60:182-94.

31. Hedgeman E, Ulrichsen SP, Carter S, Kreher NC, Malobisky KP, Braun MM, et al. Long-term health outcomes in patients with Prader-Willi Syndrome: a nationwide cohort study in Denmark. Int J Obes. 2017:41(10):1531-8. 
32. Whittington JE, Holland AJ, Webb T, Bulter J, Clarke D, Boer H. Population prevalence and estimated birth incidence and mortality rate for people with Prader-Willi syndrome in one UK health region. J Med Genet. 2001;38: 792-8.

33. Wallace I, Cunningham S, Lindsay J. The diagnosis and investigation of adrenal insufficiency in adults. Ann Clin Biochem. 2009;46(Pt 5):351-67.

\section{Publisher's Note}

Springer Nature remains neutral with regard to jurisdictional claims in published maps and institutional affiliations.

Ready to submit your research? Choose BMC and benefit from:

- fast, convenient online submission

- thorough peer review by experienced researchers in your field

- rapid publication on acceptance

- support for research data, including large and complex data types

- gold Open Access which fosters wider collaboration and increased citations

- maximum visibility for your research: over $100 \mathrm{M}$ website views per year

At $\mathrm{BMC}$, research is always in progress.

Learn more biomedcentral.com/submissions 